\title{
More sea to discover than islands to rest
}

\section{Roberto Frontini ${ }^{1,2}$}

Looking back at the history of our journal, I am proud of what we have achieved in the last 10 years. EJHP developed from a newsletter magazine at the beginning into what is now a recognised scientific journal and exciting knowledge source for every hospital pharmacist in Europe. This was and is the result of the enthusiasm of national correspondents and of all colleagues involved in the Editorial Board. However, one of them needs distinguished mention-the past Editor in Chief Professor Arnold Vulto. He was the person with the vision of a scientific practice-orientated journal written by hospital pharmacists for hospital pharmacists, he was the person who reminded us to put our patients at the centre of our actions, and he was the person who searched for the most recent developments of our profession and presented them to all European hospital pharmacists in our journal. Working with him has been inspiring, and his dedication to the European Association of Hospital Pharmacists (EAHP) has been a great input for our association. This will remain so after he has completed his work and handed over the journal to our new Editor in Chief, Professor Phil Wiffen. Professor Wiffen will continue

'European Association of Hospital Pharmacists, Brussels, Belgium

¿Universitätsklinikum Leipzig, Leipzig, Germany; Correspondence to Dr Roberto Frontini, Universitätsklinikum Leipzig, Leipzig D-04103, Germany; president@eahp.eu to enhance the quality and reputation of the journal and continue its mission and journey in becoming a centrepiece of learning exchange in our profession.

In the ocean of pharmaceutical science and practice there is still a lot to discover. We have to move on and explore, and we have to find out what best fits our new needs and requirements.

As the EAHP has grown, so has the importance of the journal-so much so that the former publisher of EJHP no longer met the EAHP's requirements for producing a modern scientific journal with a printed and full online version, a service we now offer to all our members. Joining the BMJ Group was a further step in the growing professionalism of the journal, which aspires to be a first source of information for European hospital pharmacists. However, the long publishing experience and quality of the BMJ Group is only one piece of the puzzle. The EAHP desires a journal which helps our colleagues in serving patients at the highest possible level and one which inspires young colleagues to have their first experience of publishing their research. The new Editor in Chief will help the EAHP in achieving these goals.

Our patients are individuals and need individual care, but how can we navigate in the large sea of their needs without having a compass giving us the right direction? Evidence-based guidelines and standards are paramount to finding out the real needs of our patients. You cannot measure without a measuring rod, and every effort to help patients will fail without knowing where to go. There is a need to help our colleagues understand what 'evidence' means. Evidence is not only the result of mega-trials; it is also the conscious judgement of what we know and the trust in our rationality more than in our perception, which is prone to bias. A science and practice-orientated journal like EJHP has to review the clinical evidence produced by trials and also to publish what we as hospital pharmacists discover in the daily care of our patients. We have to learn how to translate the evidence to individual patients and not to consider individuals as unpredictable exceptions of what we know.

It was not an easy decision for the Board of the EAHP to move the journal to a new publisher and now to appoint a new Editor in Chief. However, it was the logical consequence of what we want for EJHP as our official journal. We cannot rest on the beautiful island we found in the past. We have to move to the future, but also not forget the history behind us. There is more sea to discover than islands to rest.

Competing interests None.

Provenance and peer review Commissioned; internally peer reviewed.

Accepted 28 September 2012

European Journal of Hospital Pharmacy

2012;19:496. doi: 10.1136/

ejhpharm-2012-000234. 